\title{
Frequency of MRI changes suggestive of axial spondyloarthritis in the axial skeleton in a large population-based cohort of individuals aged $<45$ years
}

\author{
Xenofon Baraliakos (D) , ${ }^{1}$ Adrian Richter, ${ }^{2,3}$ Daniel Feldmann, ${ }^{1}$ Anne Ott, ${ }^{1}$ \\ Robin Buelow, ${ }^{4}$ Carsten 0 Schmidt, ${ }^{2}$ Juergen Braun ${ }^{1}$
}

\section{Handling editor Josef S \\ Smolen}

${ }^{1}$ Rheumazentrum Ruhrgebiet, Ruhr-University Bochum, Herne, Germany

${ }^{2}$ Institute for Community Medicine, University of Greifswald, Greifswald,

Germany

${ }^{3}$ German Rheumatism Research Center Berlin, Berlin, Germany ${ }^{4}$ Institute of Diagnostic Radiology and Neuroradiology, University Medicine Greifswald, Greifswald, Germany

Correspondence to Professor Juergen Braun; juergen.braun@ elisabethgruppe.de

$X B$ and $A R$ contributed equally. $\mathrm{COS}$ and JB contributed equally as senior authors.

Received 16 April 2019 Revised 12 October 2019 Accepted 4 November 2019 Published Online First 19 November 2019

Check for updates

(C) Author(s) (or their employer(s)) 2020. No commercial re-use. See rights and permissions. Published by BMJ.

To cite: Baraliakos $X$, Richter A, Feldmann D, et al. Ann Rheum Dis 2020:79:186-192.

\section{ABSTRACT}

Objective To investigate the frequency of bone marrow oedema (BME) and fatty lesions (FL) suggestive of axial spondyloarthritis (axSpA) on MRI of the spine and sacroiliac joints (SIJ) in a general population sample. Methods As part of a community-based cohort project (Study of Health in Pomerania), volunteers underwent spinal (sagittal T1/T2) and SIJ (semicoronal short tau inversion recovery) MRI examinations. Two calibrated readers evaluated the images to detect BME in SIJ and vertebral corners (VC) and FL in VC suggestive of axSpA using Assessment of SpondyloArthritis international Society definitions.

Results MRIs of 793 volunteers (49.4\% males, mean age $37.3 \pm 6.3$ years, $8.4 \%$ human leucocyte antigen-B27+) aged $<45$ years were evaluated. SIJ BME was seen in $136(17.2 \%)$, VC BME in $218(27.5 \%)$ and FL in 645 (81.4\%) volunteers. SIJ BME in $\geq 1, \geq 3$ and $\geq 5$ SIJ quadrants was seen in $136(17.2 \%), 7(0.9 \%)$ and $1(0.1 \%)$ volunteers, respectively. In $V C, B M E \geq 1, \geq 3$ and $\geq 5$ lesions were seen in $218(27.5 \%), 38(4.8 \%)$ and $6(0.8 \%)$ volunteers, respectively, while $F L \geq 1, \geq 3$ and $\geq 5$ were seen in 645 (81.3\%), 351 (44.3\%) and $185(23.3 \%)$ volunteers, respectively. Logistic regression analysis showed that BME and FL in VC were related to increasing age: $\mathrm{OR} 1.33,95 \% \mathrm{Cl} 1.02$ to 1.72 , and OR $1.73,95 \% \mathrm{Cl} 1.32$ to 2.27 , per decade increase, respectively.

Conclusions In this large population-based study, a high frequency of inflammatory and fatty MRI lesions suggestive of axSpA was found, especially in the spine. This indicates a limited value of such MRI findings for diagnosis and classification of axSpA. The increasing frequency with age suggests that mechanical factors could play a role.

\section{INTRODUCTION}

Axial spondyloarthritis (axSpA) is a chronic inflammatory disease of the axial skeleton with a prevalence between $0.1 \%$ and $1.4 \%{ }^{1}$ Classification to axSpA is possible by using the Assessment of SpondyloArthritis international Society (ASAS) classification criteria. ${ }^{2}$ According to the imaging arm of these criteria, patients aged $<45$ years with chronic back pain and a symptom onset can be classified as axSpA if either definite periarticular structural sacroiliac joint (SIJ) changes are detected on conventional radiographs (CR), or if SpA-related

\section{Key messages}

What is already known about this subject?

- The sensitivity and specificity of the Assessment of SpondyloArthritis international Society criteria for a 'positive' MRI for the classification of axial spondyloarthritis (axSpA) have been challenged due to high sensitivity with relatively low specificity.

What does this study add?

- There seems to be a relatively high frequency of inflammatory and fatty spinal/inflammatory sacroiliac joints (SIJ) and spinal MRI lesions suggestive of axSpA in the general population.

- Such MRI changes tend to occur more frequently in patients of higher age groups, suggesting an influence of a mechanical factor and potential development of osteoarthritis.

How might this impact on clinical practice or future developments?

- Caution is needed to take 'a positive MRI' as proof that a patient has axSpA, especially in the absence of clear clinical symptoms indicative of the disease.

- These data suggest that the current definition of MRI changes in the SIJ used for the classification of axSpA need an update.

bone marrow oedema (BME) are found by MRI examinations on the SIJs. Within this context, a SIJ MRI with either $\geq 2$ inflammatory lesions in form of BME in one slice or with only one BME lesion in $\geq 2$ consecutive slices has been defined as 'positive'. ${ }^{4}$ For the evaluation of the spine, a spinal MRI that is 'highly suggestive' of axSpA consists of $\geq 3$ anterior or posterior BME lesions ('spondylitis') or several vertebral corners (VC) with postinflammatory fatty lesions (FL). Also, these lesions must be visible in $\geq 2$ consecutive slices in the sagittal view of the spinal MRI. Overall, BME and FL have confirmed their value as predictors of structural damage, as seen on spinal CR during the course of the disease. ${ }^{5}$

The sensitivity and specificity of the abovementioned cut-offs for identifying axSpA have recently been tested in different cohorts with 
limited diagnostic value. ${ }^{6}$ In consequence, the value of the proposed definitions for a 'positive' MRI especially in the spine have been challenged, since a combination of both, BME and structural changes in the SIJ to classify axSpA, was found to perform superior compared with BME alone.

Overall, due to a recently reported low specificity, ${ }^{7}$ the described limitations may lead to overinterpretation of positive MRI findings in daily practice with the consequence of overdiagnosis and, consequently, overtreatment.

Therefore, we investigated the frequency of BME and FL, suggestive of axSpA, on MRI examinations of the spine and the SIJ in a general-population sample.

\section{METHODS}

\section{Study sample}

Our study sample was selected from the population-based cohort study 'Study of Health in Pomerania' (SHIP) in Germany. SHIP is part of the Community Medicine Research net of the University of Greifswald, Germany, and comprises of the separate cohorts SHIP and SHIP-TREND. Volunteers of both cohorts were sampled and selected from the two counties of North Pomerania and East Pomerania and the two cities of Greifswald and Stralsund. SHIP baseline examinations started in 1997. SHIPTREND was initiated in 2008 with a similar sampling scheme to allow for examinations of population trends. A core set of examinations (physical examinations, interviews, self-reported questionnaires and biomaterials) has constant financing. However, further examinations, such as MRI, require additional funding. Whole-body MRI (with orientations dedicated to different areas of examination) was funded as of 2008 and implemented in the second follow-up of SHIP and the baseline examinations of SHIP-TREND which were conducted in parallel. The entire SHIP project and the sampling process has been described in more detail elsewhere. ${ }^{89}$ For the present study, we planned to start double readings as soon as MRIs of $n=800$ volunteers were available. From these, $n=793$ volunteers being aged $<45$ years

\section{Cohorts of the Study of Health in Pomerania \& study population}

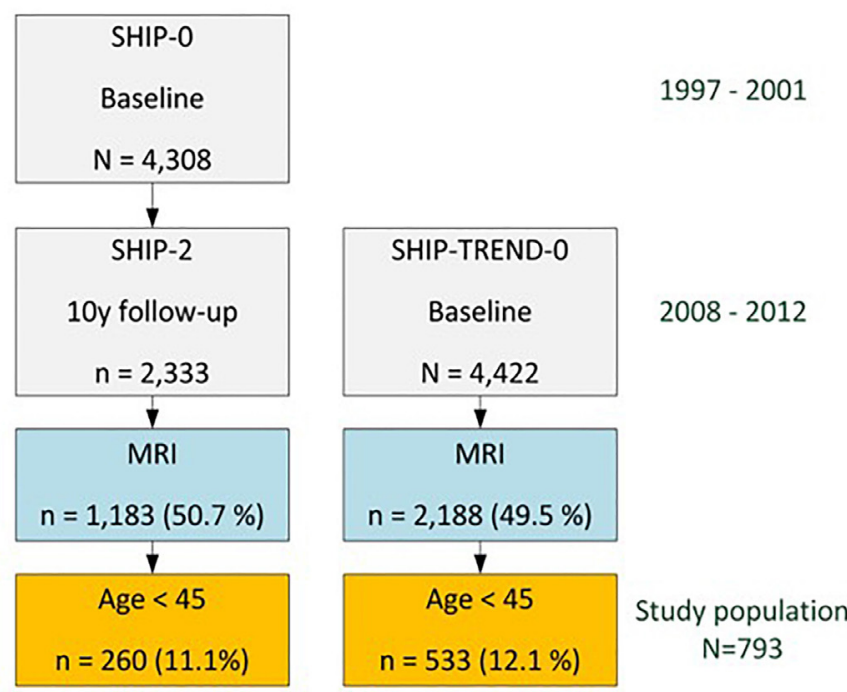

Figure 1 Cohort design of the Study of Health in Pomerania (SHIP). Percentages of MRI participation and the sample of this study refer to either SHIP-2 or SHIP-TREND. The sampling process is described in detail in Ittermann et al. ${ }^{9}$ of the MRI examination had complete MRI sets (both spine and SIJ) and were included in the analyses (figure 1).

\section{Patient and public involvement}

The SHIP study was initiated in 1997 and is conducted in the general population. Participation is based on voluntary commitment. An invitation letter to participate in the study was sent to a random selection of the population of Mecklenburg-Western Pomerania based on the data from population registries. The design of the population-based cohort study with deep phenotyping was conducted before the design of the research question targeted in the paper. This is a common approach in populationbased epidemiology. Given the large set of measurements and variables (>40 000 in total), not all uses can be anticipated a priori. However, the design of the reading of MRI images was specifically designed for this study, given the available MRI sequences. The study is not conducted in patients but in the general population. Regarding the design, participants were not involved. The recruitment was designed to ensure representativity. Participants were not involved in the invitation approach. Pilot studies with feedback from participants influenced study conduct. The SHIP study is observational and has no intended intervention. The required time for study participation is communicated in the invitation letter, newsletter and in personal phone calls arranging appointments. After participation, participants were asked whether they liked participation or had any complaints. They were also asked about their satisfaction of having participated in an MRI examination. In both cases, the vast majority was very content. Participants were involved by giving their consent to various potential uses of the results.

\section{MRI and reading of images}

All MRIs were performed at one site with the same MRI device (Magnetom Avanto, Siemens Medical Systems, Erlangen, Germany) under the same standardised protocol..$^{10} \mathrm{~T} 1$ and T2 MRI sequences in a sagittal orientation for the whole spine (figure 2A) and short tau inversion recovery (STIR) sequences in a semicoronal orientation for the SIJ (figure 2B) were available. All images were blinded for age, sex and clinical findings. Two trained readers evaluated the MR images independently in a paired fashion ${ }^{3}$ to assess BME (defined as hyperintense signal on T2-weighted and hypointense signal on T1-weighted images in VC of the spine or as hyperintense signal on STIR sequences in the SIJs) and chronic MRI lesions (FL defined as hyperintense signal on both T1-weighted and T2-weighted images of the VC).

Prior to MRI evaluation, a training session with 30 reference sets of images, including axSpA patients, guided by an experienced reader was performed. A lesion was judged as being present if fulfilling the ASAS definitions for a positive MRI for inflammatory (SIJ and VC) or FL (VC). ${ }^{411} 12$ For all definitions, a lesion had to be present in at least two consecutive slices to be counted positive. Clearly, degenerative spinal lesions defined as pathologic changes involving the vertebral endplate or being accompanied by abnormalities of the intervertebral disc (obvious dehydration, protrusion or prolapse), lesions of oedema in the lateral or posterior elements, lesions that looked like spondylodiscitis or any lesions that were suspicious to not comply to the ASAS definitions were not counted (figure 2A).

In case of disagreement between readers (lesion present or not present in SIJ or VC), discrepant cases were discussed by both readers in front of the blinded MRI, to reach an agreement.

MRI lesions were also scored based on the Berlin MRI score for BME for the SIJ and the spine. ${ }^{13}$ Once the lesions were 


\section{B}
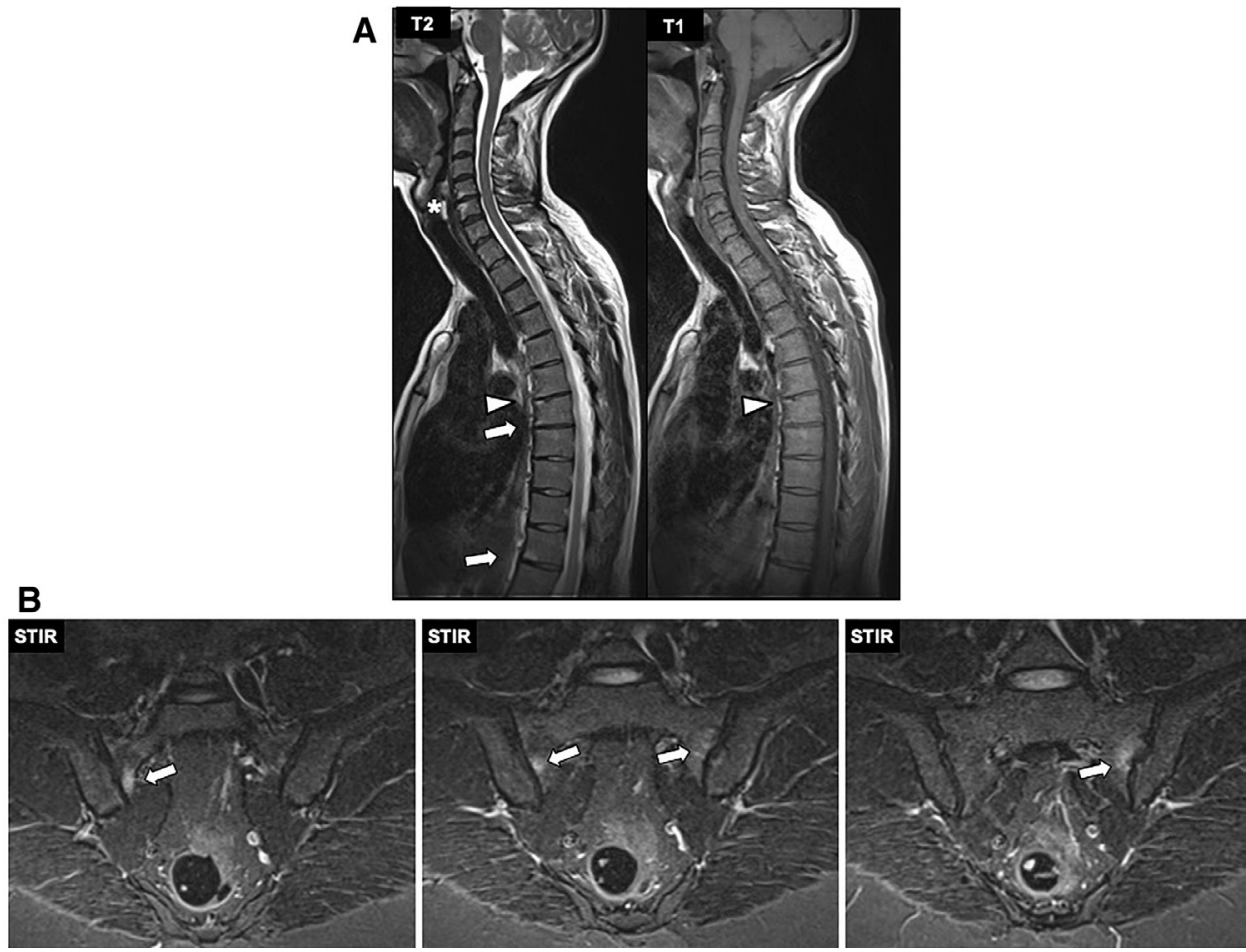

Figure 2 (A) Example of hyperintense signals in the T2-weighted and T1-weighted spinal MRI sequences of a male patient, age 39 years.

Arrowhead: Fatty lesion at the edge of a thoracic vertebra, seen as hyperintense signal in both T2-weighted and T1-weighted MRI sequences. Arrows: Bone marrow oedema at the edge of a thoracic vertebra, seen as hyperintense signal only in the T2-weighted MRI sequence. '*': Example of a lesion that was not counted as positive despite hyperintense signal on the T2-weighted sequence, due to the concomitant dehydration of the adjacent intervertebral disk and the small protrusion in this segment. (B) Example of hyperintense signals in the STIR MRI sequences of the SIJ of a female patient, age 41 years. Arrows: Bone marrow oedema seen as periarticularly located hyperintense signal on STIR MRI. SIJ, sacroiliac joints; STIR, short tau inversion recovery.

identified as described aforementioned and judged positive, BME score was calculated based on the mean score of both readers. VC FLs were captured in a binary manner (presence or absence of lesion).

\section{Collection of clinical information}

The collected clinical information was age (in years), sex, smoking (ever vs never smoked), mean spinal back pain level in the last 3 months prior to MRI examination (on a numerical rating scale (NRS-rated) $0-10$ ), physical activity (none, $<1$ hour, $1-2$ hours and $\geq 2$ hours on average per week), high-sensitivity $\mathrm{C}$ reactive protein (hsCRP, $\mathrm{mg} / \mathrm{dL}$ ), human leucocyte antigen (HLA)-B27 status (positive/negative) and body mass index category according to the WHO definition (underweight, normal, overweight and obese).

\section{Handling of missing values}

Missing values, such as not evaluable segments due to artefacts or missing clinical information, were not imputed. Results are always presented based on the available data for each parameter.

\section{Statistical analysis}

Characteristics of volunteers are summarised using descriptive statistics. Depending on the distribution of each clinical feature, the mean $\pm S D$ or the median and IQR are shown. Percentages of frequencies presented were calculated with respect to the number of available sites. Univariate logistic regression was applied to examine associations between clinical characteristics and the presence of MRI lesions.

\section{RESULTS}

\section{Clinical characteristics}

Overall, data of 793 individuals were evaluated based on the inclusion criteria aforementioned. The mean age was 37.3 (SD 6.3 years) years, $392(49.4 \%)$ were male and $401(50.6 \%)$ were female. The median NRS of back pain in the last 3 months prior to MRI examination was $2(0.0-4.0)$.

\section{Available and missing values}

The total amount of variables to be scored in the 793 volunteers was 54 (BME in 8 SIJ quadrants, and VC BME and FL each in 23 spinal segments, respectively), resulting in 6344 SIJ quadrants and 18293 VC for the analysis for BME and FL. For SIJ BME, no missings were reported. For VC BME, a total of 6/18 293 $(0.03 \%)$ segments were not available $(\mathrm{n}=2$ in segments $\mathrm{C} 2 / 3$, C3/4 and Th12/L1, respectively). For VC FL, a total of 743/18 $293(4.1 \%)$ segments were not available for scoring $(n=487$ in $\mathrm{C} 2 / 3, \mathrm{n}=205$ in $\mathrm{C} 3 / 4, \mathrm{n}=25$ in $\mathrm{C} 4 / 5, \mathrm{n}=9$ in Th2/3, $\mathrm{n}=5$ in Th1/2, $n=4$ in Th3/4, $n=2$ in C7/Th1 and in L1/2, and $n=1$ in C5/6, C6/7, Th1/2, Th2/3 and Th8/9, respectively).

Clinical information was available from all 793 patients with exception of HLA-B27, hsCRP and smoking, where information from $\mathrm{n}=756, \mathrm{n}=761$ and $\mathrm{n}=792$ patients was available, respectively (table 1).

\section{Agreement in the evaluation of images between readers}

Discrepancies between readers were seen in 1071 (2.5\%) of the scored variables. Most discrepant cases were found in variables related to VC FL ( $\mathrm{n}=943)$, while less were found in variables 
Table 1 Occurrence rate of MRI lesions of the sacroiliac joints and in the spine according to subcategories from the number of participants (' $n$ ') with available information

\begin{tabular}{|c|c|c|c|c|c|}
\hline \multirow{2}{*}{\multicolumn{2}{|c|}{$\begin{array}{l}\text { Parameter (n patients with data available) and } \\
\text { subcategory }\end{array}$}} & \multirow{3}{*}{$\begin{array}{l}\text { n (\%) patients in each } \\
\text { subcategory } \\
114(14.4 \%)\end{array}$} & \multirow{3}{*}{$\begin{array}{l}\text { Sacroiliac joints } \\
\text { n (\%) quadrants with } \\
\text { BME on MRI } \\
24(2.63 \%)\end{array}$} & \multicolumn{2}{|l|}{ Spine } \\
\hline & & & & \multirow{2}{*}{$\begin{array}{l}\text { n (\%) segments with } \\
\text { BME on MRI } \\
19(0.72 \%)\end{array}$} & \multirow{2}{*}{$\begin{array}{l}\text { n (\%) segments with FL } \\
\text { on MRI } \\
208(7.93 \%)\end{array}$} \\
\hline Age, years & $<30$ & & & & \\
\hline$(n=793)$ & $30-35$ & $120(15.1 \%)$ & $20(2.08 \%)$ & $57(2.07 \%)$ & $288(10.43 \%)$ \\
\hline & $35-40$ & $198(25.0 \%)$ & $51(3.22 \%)$ & $104(2.28 \%)$ & 499 (10.96\%) \\
\hline & $40-45$ & $361(45.5 \%)$ & $92(3.19 \%)$ & $182(2.19 \%)$ & $1309(15.77 \%)$ \\
\hline \multirow{2}{*}{$\begin{array}{l}\text { Sex } \\
(n=793)\end{array}$} & Male & $392(49.4 \%)$ & $100(3.19 \%)$ & $158(1.75 \%)$ & $1284(14.24 \%)$ \\
\hline & Female & $401(50.6 \%)$ & $87(2.71 \%)$ & $204(2.21 \%)$ & $1020(11.06 \%)$ \\
\hline \multirow{2}{*}{$\begin{array}{l}\text { hsCRP, mg/dL } \\
(n=761)\end{array}$} & Normal & $708(93 \%)$ & $169(2.98 \%)$ & $337(2.07 \%)$ & 2054 (12.61\%) \\
\hline & Increased & $53(7 \%)$ & $15(3.54 \%)$ & $18(1.48 \%)$ & $165(13.54 \%)$ \\
\hline \multirow{2}{*}{$\begin{array}{l}\text { HLA-B27 } \\
(n=756)\end{array}$} & Negative & $689(91.1 \%)$ & $157(2.85 \%)$ & $307(1.94 \%)$ & $1995(12.59 \%)$ \\
\hline & Positive & $67(8.9 \%)$ & $26(4.85 \%)$ & $38(2.47 \%)$ & $195(12.65 \%)$ \\
\hline \multirow{3}{*}{$\begin{array}{l}\text { BMl category, } \mathrm{kg} / \mathrm{m}^{2} \\
(\mathrm{n}=793)\end{array}$} & $<25$ (under-normal weight) & $357(45 \%)$ & $60(2.1 \%)$ & $159(1.94 \%)$ & $803(9.78 \%)$ \\
\hline & 25-30 (overweight) & $287(36.2 \%)$ & $83(3.61 \%)$ & $146(2.21 \%)$ & $918(13.91 \%)$ \\
\hline & $>30$ (obese) & $149(18.8 \%)$ & $44(3.69 \%)$ & $57(1.66 \%)$ & $583(17.01 \%)$ \\
\hline \multirow{2}{*}{$\begin{array}{l}\text { Ever smoked } \\
(n=792)\end{array}$} & Yes & 497 (62.8\%) & $126(3.17 \%)$ & $240(2.1 \%)$ & $1499(13.11 \%)$ \\
\hline & No & $295(37.2 \%)$ & $61(2.58 \%)$ & $122(1.8 \%)$ & $800(11.79 \%)$ \\
\hline \multirow{3}{*}{$\begin{array}{l}\text { Back pain } \\
(n=793)\end{array}$} & $\mathrm{NRS}=0$ & $342(43.1 \%)$ & $63(2.30 \%)$ & $170(2.16 \%)$ & $985(12.52 \%)$ \\
\hline & $N R S=1-3$ & $223(28.1 \%)$ & $69(3.87 \%)$ & $99(1.93 \%)$ & $648(12.63 \%)$ \\
\hline & $N R S \geq 4$ & $228(28.8 \%)$ & $55(3.02 \%)$ & $93(1.77 \%)$ & $671(12.8 \%)$ \\
\hline
\end{tabular}

Percentages were calculated on the basis of the numbers of available sites.

BME, bone marrow oedema; BMI, body mass index; FL, fatty lesions; HLA-B27, human leucocyte antigen-B27; hsCRP, high-sensitivity C reactive protein; NRS, numerical rating scale.

related to VC BME $(\mathrm{n}=88)$ or SIJ BME $(\mathrm{n}=40)$ lesions. In all discrepant cases, a consensus was reached.

\section{Frequency and quantification of BME lesions in the SIJs}

BME in the SIJ according to the ASAS definition for positive MRI was found in $136(17.2 \%)$ volunteers with little differences between males $(n=71,18.1 \%)$ and females $(n=65,16.2 \%)$, $\mathrm{p}=0.47$. In total, 187 of 6344 (2.9\%) evaluated SIJ quadrants showed BME. SIJ BME in $\geq 1$ quadrant was found in 136 $(17.2 \%)$ volunteers, while 7 volunteers $(0.9 \%)$ had $\geq 3$, and 1 $(0.1 \%)$ had $\geq 5$ SIJ quadrants showing BME lesions (table 2).

In the whole study sample, the mean number of SIJ quadrants with BME lesions was 0.24 (SD 0.62), while in the group with $\mathrm{BME}$ in SIJ, the mean number of SIJ quadrants with BME lesions was 1.38 (SD 0.83).

The distribution of SIJ quadrants with BME lesions according to subcategories based on patient's characteristics is presented in table 1.

The mean Berlin SIJ-BME score in all 793 volunteers was 0.78 (SD 1.56), while in the subgroup of the 136 with $\geq 1$ SIJ BME lesion, the median Berlin score was 2.36 (SD 2.63).

Table 2 Frequency of patients with 'positive' lesions based on different lesion cut-offs ( $\geq 1$ to $\geq 5$ lesions) for bone marrow oedema (BME) and fatty lesions (FL) in the sacroiliac joints (SIJ) and the spine

\begin{tabular}{|c|c|c|c|c|c|c|}
\hline & & \multicolumn{5}{|c|}{ Cut-off numbers of lesions } \\
\hline \multicolumn{2}{|c|}{ Site and lesion } & $\geq 1$ & $\geq 2$ & $\geq 3$ & $\geq 4$ & $\geq 5$ \\
\hline SIJ & BME & 136 & 37 & 7 & 3 & 1 \\
\hline \multirow[t]{2}{*}{ Spine } & BME & 218 & 86 & 38 & 13 & 6 \\
\hline & $\mathrm{FL}$ & 645 & 500 & 351 & 270 & 185 \\
\hline
\end{tabular}

\section{Frequency and quantification of BME lesions in the spine}

Similar to the SIJ, the frequency of VC BME according to the ASAS definition for positive MRI was almost equally distributed between males $(n=102,26.0 \%)$ and females $(n=116,28.9 \%)$ $(\mathrm{p}=0.36)$. Out of the total of 18239 spinal segments, $362(2 \%)$ showed signs of VC BME: $\geq 1$ lesion was found in $218(27.5 \%)$ volunteers, while $38(4.8 \%)$ volunteers had $\geq 3$ and 6 volunteers $(0.8 \%)$ had $\geq 5$ VC BME in any spinal segment (table 2$)$. In the whole study sample, the mean number of $\mathrm{VC}$ BME was 0.45 (SD 0.91), while in those with $\geq 1 \mathrm{VC}$ BME, it was 1.66 (SD 1.01).

The distribution VC BME in single spinal segments (cervical, thoracic or lumbar) is shown in figure 3A. The most frequently affected area by VC BME was found in the lower part of the thoracic spine. The distribution of VC BME to subcategories based on the clinical patient's characteristics is presented in table 1 .

The mean Berlin spine score in all 793 volunteers was 0.49 (SD 1.04), while in the subgroup of the 218 patients with $\geq 1 \mathrm{VC}$ $\mathrm{BME}$, the median Berlin spine score was 1.81 (SD 1.25).

\section{Frequency and quantification of FL in the spine}

There was no statistically significant difference in the frequency of VC FL between males $(n=326,83.2 \%)$ and females $(n=319$, 79.6\%) $(\mathrm{p}=0.19)$.

Out of the total of 18239 spinal segments, 2407 (13.3\%) showed signs of VC FL. Based on the individual volunteers, VC FL ( $\geq 1$ lesion) were found in $645(81.3 \%)$ volunteers, while 351 (44.3\%) volunteers had $\geq 3$ and 185 volunteers $(23.3 \%)$ had $\geq 5$ VC FL lesions in any of the spinal segments (table 2). The mean number of VC FL in all volunteers was 2.91 (SD 2.69), while the mean number of VC FL in the group of 645 volunteers with $\geq 1$ VC FL was 3.57 (SD 2.55). 
A

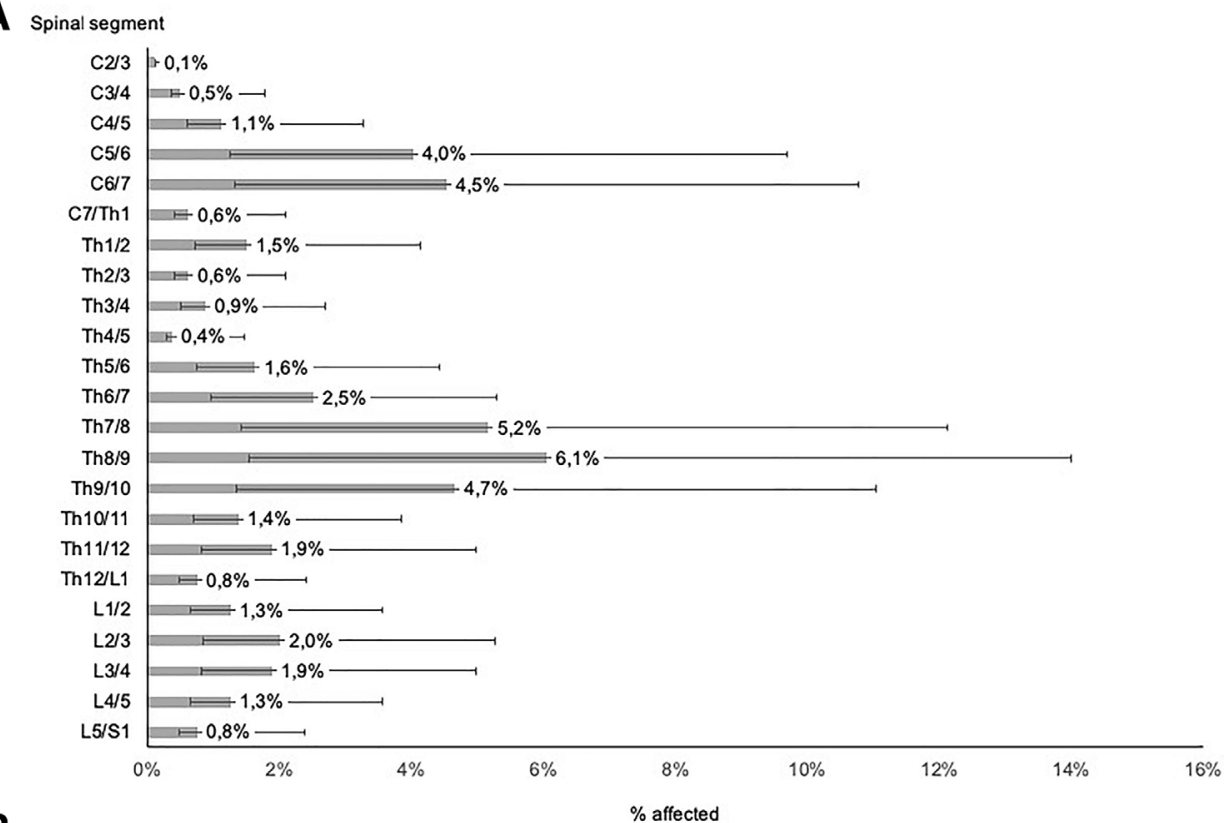

B

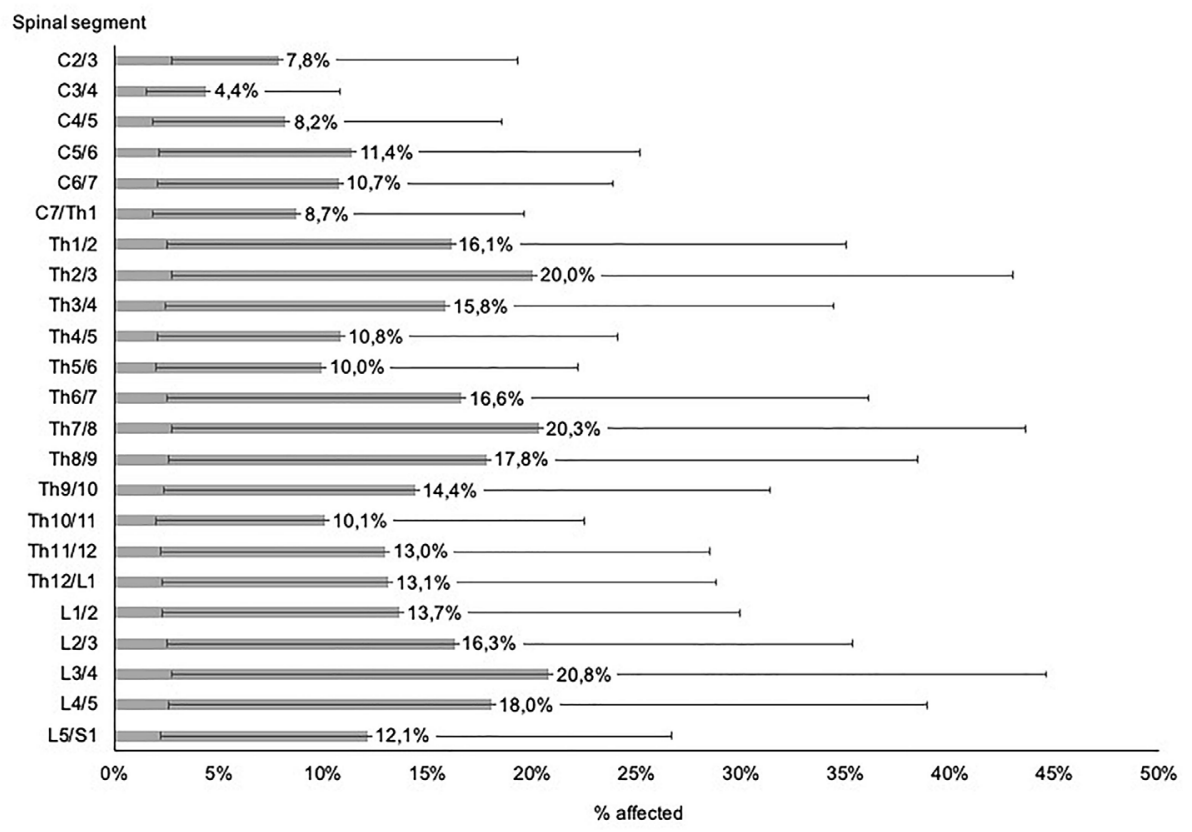

Figure 3 Distribution of spondylitis lesions ( $A$, scale $x$-axis $0 \%-16 \%$ ) and $F L(B$, scale $x$-axis $0 \%-50 \%$ ) in the 23 different vertebral segments. The numbers/percentages at each bar represent the mean proportion of lesions in each spinal segment for all participating volunteers where the respective spinal segment was available for evaluation. The lines represent the upper (to the right) and lower (to the left) confidence limit per spinal segment. C, cervical spine; FL, fatty lesions; L, lumbar spine; Th, thoracic spine.

The distribution of VC FL lesions in single spinal segments (cervical, thoracic or lumbar) is shown in figure $3 \mathrm{~B}$. The most frequently affected areas by VC FL were the upper and lower part of the thoracic spine and the lower part of the lumbar spine.

\section{Dependency of MRI findings to clinical and laboratory characteristics}

Logistic regression analysis for spine showed that VC BME and VC FL were significantly related to increasing age, per decade increase: OR 1.33, 95\% CI 1.02 to 1.72 , and OR $1.73,95 \% \mathrm{CI}$ 1.32 to 2.27 , respectively. No further clinical characteristic had a significant association with the frequency of VC BME or VC FL (table 3).

\section{DISCUSSION}

To the best of our knowledge, this study is the first to assess the frequency of both, inflammatory and fatty MRI changes of the spine and inflammatory changes of the SIJ, in a general population sample. The volunteers participating in $\mathrm{SHIP}^{8}$ a large population-based cohort study, showed a high frequency of sacroiliac and spinal MRI changes suggestive of axSpA according to the ASAS definitions. ${ }^{2}{ }^{11}$ There was a difference between inflammatory and fatty MRI changes: while the frequency of BME in SIJ or the spine (VC BME) was 17\%-28\%, VC FL were even more frequent with $>80 \%$ individuals showing such changes. However, when the cut-offs for positive scores were raised from $\geq 1$ to $\geq 3$ or $\geq 5$ lesions, this frequency decreased 
Table 3 Univariate ORs (Cls) for the association of clinical predictors and the frequency of bone marrow oedema (BME) (in sacroiliac joints (SIJ) and spine) and fatty lesions (FL) (in spine)

\begin{tabular}{|c|c|c|c|}
\hline Parameter & BME SIJ & BME spine & FL spine \\
\hline $\begin{array}{l}\text { Age (per } 10 \text { years increase), } \\
\text { years }\end{array}$ & 1.19 (0.88 to 1.62$)$ & $\begin{array}{l}1.33(1.02 \text { to } \\
1.72)\end{array}$ & $\begin{array}{l}1.73(1.32 \text { to } \\
2.27)\end{array}$ \\
\hline Sex (male vs female) & 1.14 (0.79 to 1.66$)$ & $\begin{array}{l}0.86(0.63 \text { to } \\
1.18)\end{array}$ & $\begin{array}{l}1.27(0.89 \text { to } \\
1.82)\end{array}$ \\
\hline $\mathrm{BMl}<25$ (reference), $\mathrm{kg} / \mathrm{m}^{2}$ & $\mathrm{~N} / \mathrm{A}$ & $N / A$ & $\mathrm{~N} / \mathrm{A}$ \\
\hline BMI (25-30 vs reference) & 1.46 (0.96 to 2.21$)$ & $\begin{array}{l}1.31(0.93 \text { to } \\
1.86)\end{array}$ & $\begin{array}{l}1.48(1.00 \text { to } \\
2.19)\end{array}$ \\
\hline BMI (>30 vs reference) & 1.61 (0.98 to 2.65) & $\begin{array}{l}1.09(0.71 \text { to } \\
1.68)\end{array}$ & $\begin{array}{l}3.27(1.76 \text { to } \\
6.07)\end{array}$ \\
\hline Smoking (ever vs never) & $1.25(0.84$ to 1.84$)$ & $\begin{array}{l}1.06 \text { (0.77 to } \\
1.47)\end{array}$ & $\begin{array}{l}1.00 \text { (0.69 to } \\
1.44)\end{array}$ \\
\hline $\begin{array}{l}\text { Back pain last } 3 \text { months (yes } \\
\text { vs no) }\end{array}$ & $1.32(0.90$ to 1.93$)$ & $\begin{array}{l}1.00(0.73 \text { to } \\
1.37)\end{array}$ & $\begin{array}{l}0.91(0.63 \text { to } \\
1.31)\end{array}$ \\
\hline HLA-B27 (pos. vs neg.) & 1.27 (0.68 to 2.36$)$ & $\begin{array}{l}1.15(0.66 \text { to } \\
1.99)\end{array}$ & $\begin{array}{l}1.14(0.58 \text { to } \\
2.24)\end{array}$ \\
\hline hsCRP $(>0.5 \mathrm{vs}<0.5), \mathrm{mg} / \mathrm{dL}$ & 0.96 (0.46 to 2.03$)$ & $\begin{array}{l}0.83(0.43 \text { to } \\
1.58)\end{array}$ & $\begin{array}{l}1.13(0.54 \text { to } \\
2.37)\end{array}$ \\
\hline $\begin{array}{l}\text { Physical activity } \\
\text { (none=reference) }\end{array}$ & $\mathrm{N} / \mathrm{A}$ & $\mathrm{N} / \mathrm{A}$ & $\mathrm{N} / \mathrm{A}$ \\
\hline$>2$ hours vs none & 0.79 (0.47 to 1.35$)$ & $\begin{array}{l}0.88(0.55 \text { to } \\
1.39)\end{array}$ & $\begin{array}{l}1.30(0.75 \text { to } \\
2.26)\end{array}$ \\
\hline $1-2$ hours vs none & $0.73(0.45$ to 1.20$)$ & $\begin{array}{l}0.89(0.58 \text { to } \\
1.36)\end{array}$ & $\begin{array}{l}1.01(0.62 \text { to } \\
1.63)\end{array}$ \\
\hline$<1$ hour vs none & 0.64 (0.38 to 1.08$)$ & $\begin{array}{l}0.85(0.55 \text { to } \\
1.32)\end{array}$ & $\begin{array}{l}0.97(0.59 \text { to } \\
1.59)\end{array}$ \\
\hline
\end{tabular}

BMI, body mass index; HLA-B27, human leucocyte antigen-B27; hsCRP, high-sensitivity C reactive protein; N/A, not applicable; neg., negative; pos., positive.

substantially. This suggests a good performance of the existing definitions of a 'positive spinal MRI' (cut-off $\geq 5$ lesions ${ }^{11}$ ) related to specificity. Furthermore, these results are also in line with previously published data on SIJ MRIs only or in groups with smaller patient numbers ${ }^{7}$ from different samples, such as athletes ${ }^{14}$ and military recruits. ${ }^{15}$ There, the relative frequency of BME lesions ranged largely between $6 \%$ and $60 \%$. The only study that also considered a low number of healthy volunteers ${ }^{7}$ reported a proportion of SIJ BME of 23.4\%, which is comparable to our study. On the other hand, the rates of volunteers presenting with VC BME or FL are different from data reported in another study, also with low numbers of volunteers with spinal MRIs, ${ }^{6}$ with rates of $43.8 \%$ of subjects showing $\geq 1 \mathrm{VC}$ $\mathrm{BME}$ and $65 \%$ of subjects showing $\geq 1 \mathrm{VC}$ FL. Overall, our data suggest that the sensitivity of MRI to detect minor changes is high and that caution is needed to take 'a positive MRI' as proof for a patient having axSpA. This statement holds for both, diagnosis and classification of axSpA. Importantly, the quantification of lesions based on the Berlin MRI score for the SIJ and the spine indicated a rather low extent of the detected BME lesions, with median scores around zero for BME at both examined sites of the axial skeleton. This finding is consistent with recent data showing that 'deep' lesions (defined as signal $\geq 1 \mathrm{~cm}$ from the articular surface) were almost exclusively found in axSpA patients but not in other conditions. ${ }^{7}$ Our large populationbased sample confirms this result for the SIJ and extends it to $\mathrm{BME}$ in the spine. Taken together, these findings are important for the diagnosis and classification of axSpA.

One other important finding of our study is the dependency of spinal MRI lesions to age. Both, VC BME and FL, were more frequent in older individuals_even below the age of 45 years. Physical activity had no impact on the frequency of BME or FL. Thus, minor inflammatory MRI changes may occur in individuals with no evidence of an inflammatory condition. This has already guided us to challenge the specificity of small MRI signals at the SIJ, the spine and the entheses for axSpA. ${ }^{16}$

Whether the occurrence of the described MRI signals can be attributed to mechanical stress needs further study. In that regard, one recent study has clearly shown that degenerative changes in the axial skeleton are associated with pain, also in patients with axSpA. ${ }^{17}$ Small changes may just disappear once the mechanical load is gone. If mechanical stress continues to be present, this will probably be different. It seems very likely that the cause of the detected MRI changes is of mechanical nature and that the immune system has no or a minor role in that process. To our opinion, these MRI signals are early degenerative changes which potentially lead to osteoarthritis later in life. According to two recent publications, there is no doubt that degenerative changes, potentially in addition to BME, are already present in young patients with and without axSpA. ${ }^{18} 19$

Another result of this study worth mentioning is the distribution of VC BME and FL in the spine. The majority of lesions were observed in the lower part of the thoracic spine. This pattern of involvement confirms earlier data spinal MRIs of patients with radiographic axSpA from our group ${ }^{20}$ and also recent CT data ${ }^{21}$ and is also in line with the well-known higher mechanical load of this spinal area in other conditions, as compared with the cervical or the lumbar spine alone. ${ }^{22}$

Since all MRIs were performed in the same centre, under the same standardised protocol and with the same device, there is no reason to consider methodologic variability as a limitation of our study.

A limitation of our study may be that the participants were volunteers from the general population, and potential selection bias might have occurred. However, another population-based study gives evidence of a rather small impact of initial nonresponse and attrition on back pain-related point estimates. ${ }^{23} \mathrm{In}$ line with this, the reported back pain in the past 7 days in our sample was $41 \%$. This is not much different from epidemiologic data provided in recent reviews. ${ }^{19}{ }^{24}$ Furthermore, HLA-B27 frequency in our cohort is in line with other population-based results. $^{25}$

Since many axSpA patients are not diagnosed or diagnosed late, ${ }^{26}$ we cannot exclude that there were axSpA patients in our cohort. With an estimated prevalence of about $1 \%,{ }^{1}$ it is possible that about 6-10 individuals in this study could indeed have (yet undiagnosed) axSpA. It is, for example, possible that those subjects with a lot of MRI changes or more HLA-B27 positives with chronic back pain did have the disease. Furthermore, the fact that we are currently unable to provide any follow-up information of the study volunteers may be considered as a limitation. However, this was currently not the target of the analyses presented here. Such data would be interesting for the understanding of the natural course of the described lesions and the possible development of defined inflammatory rheumatic conditions. Finally, an important limitation of the study is also the fact that the MRI sequences available in the cohort were not the ones ideally recommended by ASAS. ASAS recommends that sequences designed to identify inflammation or depict structural damage are simultaneously reviewed-this was, for technical reasons, not done in this study. For the SIJ, we had only STIR but no T1 images available. Nevertheless, since we were looking for clear lesions of BME, we do not think that missing the information on T1 images has a significant impact on the results, but it may even have led to an underestimation of 'positive' images. On the other hand, for spinal MRIs, we only had T1 and T2 but no STIR images available. Although it is not stated explicitly 
in the ASAS paper on descriptions of spinal MRI lesions, ${ }^{11}$ the vast majority of the studies have been made by using the STIR sequence for the detection of inflammatory lesions, due to the high sensitivity of this sequence. ${ }^{27}$ In the present study, we evaluated inflammatory lesions based on the occurrence of high-intensity signal on the available T2-weighted sequences and only if the corresponding area on T1-weighted sequences was showing a hypointense signal. Similar to the SIJ, this might have influenced our data towards a rather lower prevalence of lesions due to the missing, sensitive, STIR lesion, but on the other hand, may have also led to a more specific evaluation of the pathologic findings.

In conclusion, in this first large population-based study, a high frequency of inflammatory and fatty vertebral corner lesions and inflammatory SIJ MRI lesions suggestive of axSpA has been found. These data suggest that the current definition of MRI changes used for the classification of axSpA requires an update. A small size and a small number of MRI signals detected in the axial skeleton of patients under suspicion of axSpA is inconclusive for diagnosis or classification of axSpA, while higher cut-offs may be more adequate for assessment of positive axSpA-related MRI findings. Finally, such MRI changes tend to occur more frequently in individuals of higher age groups, suggesting the influence of a mechanical factor and potential development of osteoarthritis.

Correction notice This article has been corrected since it published Online First. The corresponding author details have been updated.

Acknowledgements SHIP is part of the Community Medicine Research net of the University Medicine of Greifswald, which is supported by the Federal State of Mecklenburg-West Pomerania, Germany, as well as by a joint grant from Siemens Healthineers, Erlangen.

Contributors $\mathrm{XB}$ and JB: Idea, coordination of the readings, data interpretation and writing of the manuscript. AR: Coordination of the readings, data analysis, data interpretation and editing of the manuscript. DF and AO: Reading of images. RB: Coordination of MR data acquisition, data interpretation and editing of the manuscript. COS: Coordination of SHIP, coordination of the readings, data analysis, data interpretation and editing of the manuscript.

Funding The authors have not declared a specific grant for this research from any funding agency in the public, commercial or not-for-profit sectors.

Competing interests None declared.

Patient consent for publication Not required.

Ethics approval The study was approved by the local ethics committee of the University Medicine of Greifswald.

Provenance and peer review Not commissioned; externally peer reviewed.

Data availability statement Data are available on reasonable request. All data relevant to the study are included in the article or uploaded as supplementary information.

ORCID ID

Xenofon Baraliakos http://orcid.org/0000-0002-9475-9362

\section{REFERENCES}

1 Braun J, Sieper J. Ankylosing spondylitis. Lancet 2007;369:1379-90.

2 Rudwaleit M, van der Heijde D, Landewé $R$, et al. The development of assessment of spondyloarthritis International Society classification criteria for axial spondyloarthritis (Part II): validation and final selection. Ann Rheum Dis 2009;68:777-83.

3 Lambert RGW, Bakker PAC, van der Heijde D, et al. Defining active sacroiliitis on MRI for classification of axial spondyloarthritis: update by the ASAS MRI Working group. Ann Rheum Dis 2016;75:1958-63.

4 Rudwaleit M, Jurik AG, Hermann K-GA, et al. Defining active sacroiliitis on magnetic resonance imaging (MRI) for classification of axial spondyloarthritis: a consensual approach by the ASAS/OMERACT MRI group. Ann Rheum Dis 2009;68:1520-7.
5 Baraliakos X, Heldmann F, Callhoff J, et al. Which spinal lesions are associated with new bone formation in patients with ankylosing spondylitis treated with anti-TNF agents? a long-term observational study using MRI and conventional radiography. Ann Rheum Dis 2014:73:1819-25.

6 Weber U, Zhao Z, Rufibach K, et al. Diagnostic utility of candidate definitions for demonstrating axial spondyloarthritis on magnetic resonance imaging of the spine. Arthritis Rheumatol 2015;67:924-33.

7 de Winter J, de Hooge M, van de Sande $M$, et al. Magnetic resonance imaging of the Sacroiliac joints indicating sacroiliitis according to the assessment of spondyloarthritis International Society definition in healthy individuals, runners, and women with postpartum back pain. Arthritis Rheumatol 2018;70:1042-8.

8 Völzke H, Alte D, Schmidt CO, et al. Cohort profile: the study of health in Pomerania. Int J Epidemiol 2011:40:294-307.

9 Ittermann T, Wittfeld K, Nauck M, et al. High thyrotropin is associated with reduced hippocampal volume in a population-based study from Germany. Thyroid 2018;28:1434-42

10 Hegenscheid K, Kühn JP, Völzke H, et al. Whole-Body magnetic resonance imaging of healthy volunteers: pilot study results from the population-based SHIP study. Rofo 2009;181:748-59.

11 Hermann K-GA, Baraliakos X, van der Heijde DMFM, et al. Descriptions of spinal MRI lesions and definition of a positive MRI of the spine in axial spondyloarthritis: a consensual approach by the ASAS/OMERACT MRI study Group. Ann Rheum Dis 2012:71:1278-88.

12 Sieper J, Rudwaleit M, Baraliakos X, et al. The assessment of spondyloarthritis International Society (ASAS) Handbook: a guide to assess spondyloarthritis. Ann Rheum Dis 2009;68 Suppl 2:ii1-44.

13 Haibel H, Rudwaleit M, Brandt HC, et al. Adalimumab reduces spinal symptoms in active ankylosing spondylitis: clinical and magnetic resonance imaging results of a fifty-two-week open-label trial. Arthritis Rheum 2006;54:678-81.

14 Weber U, Jurik AG, Zejden A, et al. Frequency and Anatomic Distribution of Magnetic Resonance Imaging Features in the Sacroiliac Joints of Young Athletes: Exploring "Background Noise" Toward a Data-Driven Definition of Sacroiliitis in Early Spondyloarthritis. Arthritis Rheumatol 2018;70:736-45.

15 Varkas G, de Hooge M, Renson T, et al. Effect of mechanical stress on magnetic resonance imaging of the sacroiliac joints: assessment of military recruits by magnetic resonance imaging study. Rheumatology 2018;57:508-13.

16 Braun J, Baraliakos X. Active and chronic sacroiliitis spondylitis and enthesitis, how specific are imaging findings for axial spondyloarthritis? Rheumatology 2018.

17 de Hooge M, de Bruin F, de Beer L, et al. Is the site of back pain related to the location of magnetic resonance imaging lesions in patients with chronic back pain? results from the spondyloarthritis caught early cohort. Arthritis Care Res 2017:69:717-23.

18 de Bruin F, ter Horst S, Bloem HL, et al. Prevalence of degenerative changes of the spine on magnetic resonance images and radiographs in patients aged $16-45$ years with chronic back pain of short duration in the spondyloarthritis caught early (space) cohort. Rheumatology 2016:55:56-65.

19 de Bruin F, Treyvaud MO, Feydy A, et al. Prevalence of degenerative changes and overlap with spondyloarthritis-associated lesions in the spine of patients from the DESIR cohort. RMD Open 2018;4:e000657.

20 Baraliakos X, Landewé R, Hermann K-G, et al. Inflammation in ankylosing spondylitis: a systematic description of the extent and frequency of acute spinal changes using magnetic resonance imaging. Ann Rheum Dis 2005;64:730-4.

21 de Koning $A$, de Bruin $F$, van den Berg $R$, et al. Low-Dose $C T$ detects more progression of bone formation in comparison to conventional radiography in patients with ankylosing spondylitis: results from the SIAS cohort. Ann Rheum Dis 2018;77:293-9.

22 Qiu T-X, Teo E-C, Lee K-K, et al. Validation of T10-T11 finite element model and determination of instantaneous axes of rotations in three anatomical planes. Spine 2003:28:2694-9.

23 Schmidt CO, Raspe $\mathrm{H}$, Pfingsten $\mathrm{M}$, et al. Does attrition bias longitudinal populationbased studies on back pain? Eur J Pain 2011;15:84-91.

24 Hoy D, Brooks P, Blyth F, et al. The epidemiology of low back pain. Best Pract Res Clin Rheumatol 2010;24:769-81.

25 Braun J, Bollow M, Remlinger G, et al. Prevalence of spondylarthropathies in HLA-B27 positive and negative blood donors. Arthritis Rheum 1998:41:58-67.

26 Regierer AC, Weiß A, Baraliakos X, et al. [RABBIT-SpA: a new disease register for axial spondyloarthritis and psoriatic arthritis]. Z Rheumato/ 2019. doi:10.1007/s00393019-0613-z

27 Baraliakos X, Hermann K-GA, Landewé $\mathrm{R}$, et al. Assessment of acute spinal inflammation in patients with ankylosing spondylitis by magnetic resonance imaging: a comparison between contrast enhanced T1 and short tau inversion recovery (stir) sequences. Ann Rheum Dis 2005;64:1141-4. 